\title{
Glutamate-Positive Neurons in the Somatic Sensory Cortex of Rats and Monkeys
}

\author{
Fiorenzo Conti, ${ }^{a}$ Aldo Rustioni, Peter Petrusz, and Andrew C. Towle \\ Departments of Anatomy and Physiology, University of North Carolina at Chapel Hill, Chapel Hill, North Carolina 27514
}

The morphology and laminar distribution of neurons labeled with an antiserum prepared against glutamic acid (Glu) conjugated to keyhole limpet hemocyanin have been studied in the somatic sensory cortex of rats and monkeys. In both species, the vast majority of immunostained neurons are pyramidal; some nonpyramidal neurons are also present. Positive neurons are observed in all cortical layers, although variations are found in the percentage of Glu-positive neurons in the different layers. In rats they are most numerous in layer V $(36 \%)$, followed by layer II $(33 \%)$, layer III $(32 \%)$, and layer VI $(29 \%)$. In layer IV, $13 \%$ of all neurons are positive. Immunoreactive neurons are very sparse in layer $\mathrm{I}$. In monkeys, Glu-positive neurons represent $51 \%$ of all neurons in layer V, $49 \%$ in layer $\mathrm{III}, \mathbf{4 0} \%$ in layers II and VI, and $19 \%$ in layer IV. No differences are evident in the laminar distribution of Glu-positive neurons among cytoarchitectonic areas $3 a, 3 b, 1$, and 2 . As in rats, Glu-positive neurons are very sparse in layer $\mathrm{l}$. Since Glu and GABA metabolisms are closely related, double-labeling experiments were performed in which thin, adjacent paraffin sections were stained alternately with the anti-Glu serum and with an anti-GABA serum. The 2 populations are almost completely segregated, even though a small fraction of neurons $(<5 \%)$ are labeled by the antisera against both antigens.

The present results show that a large population of cortical neurons stain positively with an anti-Glu serum and that most of these are pyramidal neurons in layers II, III, V, and VI. The possibility that labeling may be related to increased levels of the metabolic pool of Glu cannot be ruled out. However, from the morphology and laminar distribution of Glu-positive neurons it is possible that, as indicated by more indirect methods, Glu or a closely related compound can be the neurotransmitter in the descending corticofugal and the associative and callosal corticocortical pathways.

Exploration of the chemical anatomy of the cerebral cortex has progressed rapidly in the last decade, largely as a result of the availability of antisera directed toward molecules believed to act as neurotransmitters. The immunocytochemical approach

\footnotetext{
Received Sept. 2, 1986; revised Nov. 10, 1986; accepted Dec. 4, 1986.

This work was supported by USPHS Grants NS-12440 and NS-16264. We gratefully acknowledge K. Phend for histological assistance and M. Kuczynski for editorial revisions.

Correspondence should be addressed to Dr. Aldo Rustioni, Department of Anatomy, University of North Carolina at Chapel Hill, 108 Swing Building, 217 H, Chapel Hill, NC 27514.

a Present address: Istituto di Fisiologia Umana, Università di Ancona, Via Ranieri-Monte d'Ago, I-60131 Ancona, Italy.

Copyright (C) 1987 Society for Neuroscience $0270-6474 / 87 / 061887-15 \$ 02.00 / 0$
}

has been instrumental in identifying peptide-containing neurons (for reviews, see Parnavelas and McDonald, 1983; Emson and Hunt, 1984; Jones and Hendry, 1986), GABAergic (Houser et al., 1984), cholinergic (Houser et al., 1985) neurons, and monoamine fibers and terminals (Descarries et al., 1984). Knowledge of other transmitter candidates in the cortex, particularly those associated with pyramidal neurons, has lagged behind. Following the demonstration of a strong excitatory effect of glutamic acid (Glu) and aspartic acid (Asp) on cortical neurons (Krnjević and Phillis, 1963), anatomical evidence, recently reviewed by Ottersen and Storm-Mathisen (1984b) and Streit (1984), has accumulated suggesting that these amino acids may be important neurotransmitters for cortical functions. A major advance in the attempt to identify glutamergic neurons in the cerebral cortex was the demonstration that Glu can be visualized by immunocytochemistry with antibodies raised against this amino acid, coupled with glutaraldehyde to BSA (Storm-Mathisen et al., 1983; Ottersen and Storm-Mathisen, 1984a). In perfusionfixed brains, Storm-Mathisen and his collaborators stained the cytoplasm, nucleoli and nuclei of both pyramidal and nonpyramidal neurons, and did not observe laminar variations in the cerebral cortex of rats and mice. Using an antiserum against glutaminase (GLNase), an enzyme that converts glutamine into glutamate, Donoghue et al. (1985) found GLNase-positive neurons mainly in the infragranular layers of the cerebral cortex of rats, guinea pigs, and monkeys, and observed differences in the density of the same neurons in layer III among the various cytoarchitectonic fields of the sensory cortex in monkeys.

Some uncertainties about the laminar distribution of putative glutamergic neurons in the cerebral cortex also emerge from studies using other techniques. Following multiple injections of ${ }^{3} \mathrm{H}$-Glu in the visual cortex of squirrel monkeys, labeled neurons were observed mainly in layers V and VI (Carroll and WongRiley, 1985). Nevertheless, other investigators, also using autoradiographic techniques, have stressed the presence of neurons that may use Glu or Asp or both as neurotransmitters in layers II and III (Contamina et al., 1984; Manzoni et al., 1986).

We reinvestigated putative glutamergic cortical neurons using a new antiserum directed against Glu (Hepler et al., 1986, 1987). Here we present quantitative data on the laminar distribution and morphology of neurons labeled by this antibody. Preliminary reports of this work have appeared in abstract form (Conti et al., 1985, 1986).

\section{Materials and Methods}

Preparation of rat tissue. Observations were carried out mainly on 24 adult Sprague-Dawley rats. In some rats, $1 \mu \mathrm{l}$ of a solution of colchicine in physiological saline $(100 \mu \mathrm{g} / \mu \mathrm{l})$ was injected into the lateral ventricle via a glass micropipette $(80-100 \mu \mathrm{m}$ tip diameter); in 1 rat, $0.2 \mu \mathrm{l}$ of 
Table 1. Summary of the animals used for the immunocytochemical study of SI with details about fixation and histological procedures

\begin{tabular}{|c|c|c|c|c|c|c|c|}
\hline Animal & Colchicine & Fixation & Postfixation & Sectioning & $\begin{array}{l}\text { Thickness } \\
(\mu \mathrm{m})\end{array}$ & PAP & $\mathrm{ABC}$ \\
\hline \multicolumn{8}{|l|}{ Rat } \\
\hline $237 / 261$ & - & $\begin{array}{l}4 \% \text { paraformaldehyde } \\
\quad+0.3 \% \text { glutaraldehyde }\end{array}$ & Overnight & Vibratome & 25 & + & \\
\hline $243 / 251 / 258$ & - & $5 \%$ glutaraldehyde & $3-12 \mathrm{hr}$ & Vibratome & 25 & + & \\
\hline 269 & - & $\begin{array}{l}4 \% \text { paraformaldehyde } \\
+0.1 \% \text { glutaraldehyde }\end{array}$ & Overnight & Vibratome & 25 & + & \\
\hline 270 & - & $\begin{array}{l}4 \% \text { paraformaldehyde } \\
+0.5 \% \text { zinc salycilate }\end{array}$ & Overnight & $\begin{array}{l}\text { Vibratome } \\
\text { paraffin }\end{array}$ & $\begin{array}{l}25 \\
4 \text { and } 7\end{array}$ & + & + \\
\hline $272 / 273 / 288$ & $\begin{array}{l}\text { only \#288 } \\
\text { (in cortex) }\end{array}$ & $\begin{array}{l}4 \% \text { paraformaldehyde } \\
\quad+0.5 \% \text { glutaraldehyde }\end{array}$ & Overnight & $\begin{array}{l}\text { Vibratome } \\
\text { paraffin }\end{array}$ & $\begin{array}{r}25 \\
7\end{array}$ & $\begin{array}{l}+ \\
+\end{array}$ & + \\
\hline 287 & $+($ in $\mathrm{LV})$ & $\begin{array}{l}4 \% \text { paraformaldehyde } \\
\quad+0.5 \% \text { glutaraldehyde }\end{array}$ & Overnight & Vibratome & 25 & + & \\
\hline $276 / 291 / 310$ & + & $4 \%$ paraformaldehyde & Overnight & Vibratome & 25 & + & \\
\hline $277 / 335 / 353$ & - & $4 \%$ paraformaldehyde & Overnight & Vibratome & 25 & + & \\
\hline 292 & $+{ }_{\text {(in LV) }}$ & $\begin{array}{l}4 \% \text { paraformaldehyde } \\
+0.2 \% \text { glutaraldehyde }\end{array}$ & Overnight & Vibratome & 25 & + & \\
\hline 313 & - & $\begin{array}{l}2 \% \text { paraformaldehyde } \\
\quad+0.2 \% \text { picric acid }\end{array}$ & Overnight & Vibratome & 25 & + & \\
\hline $381 / 384$ & - & $4 \%$ paraformaldehyde & Ovcrnight & paraffin & 4 & & + \\
\hline 394 & - & $4 \%$ carbodiimide & $\begin{array}{l}36 \mathrm{hr} \text { in } 4 \% \\
\text { paraformaldehyde }\end{array}$ & $\begin{array}{l}\text { Vibratome } \\
\text { paraffin }\end{array}$ & $\begin{array}{r}25 \\
4\end{array}$ & & $\begin{array}{l}+ \\
+\end{array}$ \\
\hline 395 & - & $4 \%$ paraformaldehyde & $\begin{array}{l}3 \mathrm{~d} \text { in } 4 \% \\
\text { paraformaldehyde }\end{array}$ & paraffin & 4 & & + \\
\hline 399 & - & $4 \%$ carbodiimide & $\begin{array}{l}36 \mathrm{hr} \text { in } 4 \% \\
\text { paraformaldehyde }\end{array}$ & Vibratome & 25 & & + \\
\hline \multicolumn{8}{|l|}{ Monkey } \\
\hline 94 & - & $4 \%$ paraformaldehyde & Overnight & Vibratome & 25 & + & \\
\hline 96 & - & $4 \%$ carbodiimide & $\begin{array}{l}3 \mathrm{~d} \text { in } 4 \% \\
\text { paraformaldehyde }\end{array}$ & Vibratome & 25 & & + \\
\hline
\end{tabular}

Abbreviations: $\mathrm{PAP}$, peroxidase-antiperoxidase; $\mathrm{ABC}$, avidin-biotin complex; $\mathrm{LV}$, lateral ventricle.

colchicine in saline was injected directly into the cortex (Table 1). Rats were perfused transcardially with physiological saline and thereafter by 1 of the following fixatives: (1) $5 \%$ glutaraldehyde in $0.1 \mathrm{M}, \mathrm{pH} 7.4$, phosphate buffer; (2) $4 \%$ paraformaldehyde and $0.2,0.3,0.5,1$, or $3 \%$ glutaraldehyde in $0.1 \mathrm{M}$ phosphate buffer; (3) $0.5 \%$ zinc salicylate, $0.45 \%$ sodium chloride, and 4\% paraformaldehyde (Mugnaini and Dahl, 1983); (4) $4 \%$ paraformaldehyde in $0.1 \mathrm{M}$ phosphate buffer; (5) $2 \%$ paraformaldehyde and $0.2 \%$ picric acid in $1 \mathrm{~m}$ phosphate buffer (Stefanini et al., 1967); or (6) $4 \%$ carbodiimide in $0.1 \mathrm{M}$ phosphate buffer. The brains were removed from the skull and postfixed for 2-36 hr (Table 1). A coronal, 3- to 5-mm-thick slab containing the primary somatosensory cortex (SI), as indicated by the overlying pattern of blood vessels (see below), was cut and rinsed in phosphate buffer. From these slabs, 48 blocks (i.e., 1 from each hemisphere) containing SI were obtained. Vibratome sections ( $25 \mu \mathrm{m}$ thick) were cut from most of the blocks and collected in serial groups of 5 . Of the series of 5 sections, one was processed for immunocytochemistry and one was stained with either $0.1 \%$ cresyl violet or $0.25 \%$ thionine. Seven blocks were rinsed in PBS, dehydrated in ethanol, cleared in toluene, and embedded in paraffin. Sections, $4 \mu \mathrm{m}$ thick, were cut serially and mounted individually on subbed slides; $30-50$ slides were prepared from each paraffin block. Before immunocytochemical processing, sections were rehydrated through descending concentrations of ethanol in PBS and rinsed in phosphate buffer.

Preparation of monkey tissue. The brains from 2 monkeys (Macaca fascicularis) were also used. One monkey (M94) was perfused with physiological saline followed by a solution of $4 \%$ paraformaldehyde in phosphate buffer, the other (M96) with physiological saline followed by a solution of $4 \%$ carbodiimide in phosphate buffer (Table 1). After autopsy, the brains were postfixed in $4 \%$ paraformaldehyde in phosphate buffer overnight (M94) or for three d (M96). Blocks were excised from the middle tier of the postcentral gyrus on each side, and $25-\mu \mathrm{m}$-thick parasagittal sections were cut with a Vibratome.

Antisera. The Glu antiserum ( $\# 482 a$ ) used in the present investigation was raised in a rabbit against Glu conjugated to keyhole limpet hemocyanin (HC) with glutaraldehyde (Hepler et al., 1986; Toomim et al., 1986). Immunoabsorption and immunoblot specificity tests have shown that this antiserum does not cross-react with Asp, GABA, $\beta$-alanine, $\mathrm{L}$-glutamine, $\alpha$-amino butyric acid, L-leucine, $\epsilon$-amino- $n$-caproate, taurine, glycine, $\alpha$-amino- $\beta$-hydroxybutyrate, $\Delta$-amino- $n$-valerate, $\Delta$-amino-levulinate, L-asparagine, succinate, oxalacetate, L-malate, fumarate, $N$-acetyl-L-aspartate, $\alpha$-chetoglurate, isoleucine, L-ornithine, $\mathrm{HC}$, or HC-glutaraldehyde; details of the characterization of the Glu antiserum are reported in another publication (Hepler et al., 1987). Method and antiserum specificities for Glu were tested for the present material by omitting the primary antiserum from the staining sequence or by staining with primary antiserum incubated overnight with Glu$\mathrm{HC}$, respectively. In the first case, no staining was observed (Fig. 1A); in the second case, the staining was completely blocked by $303 \mu \mathrm{g}$ of Glu- $\mathrm{HC} / \mathrm{ml}$ (Fig. $1 B$ ). Different dilutions of the antisera were tested: Best results, as judged by neuronal staining and signal-to-noise ratio, were obtained with dilutions $1: 12,000$ and 1:6000 for free-floating (Fig. $1 C)$ and paraffin sections, respectively.

To control for colocalization of Glu and GABA (see Discussion), GABA antiserum raised in rats against GABA conjugated to keyhole limpet $\mathrm{HC}$ by glutaraldehyde was also used. The specificity of this antiserum has been documented elsewhere (Lauder et al., 1986). The dilution used for the GABA antiserum was 1:2000. 

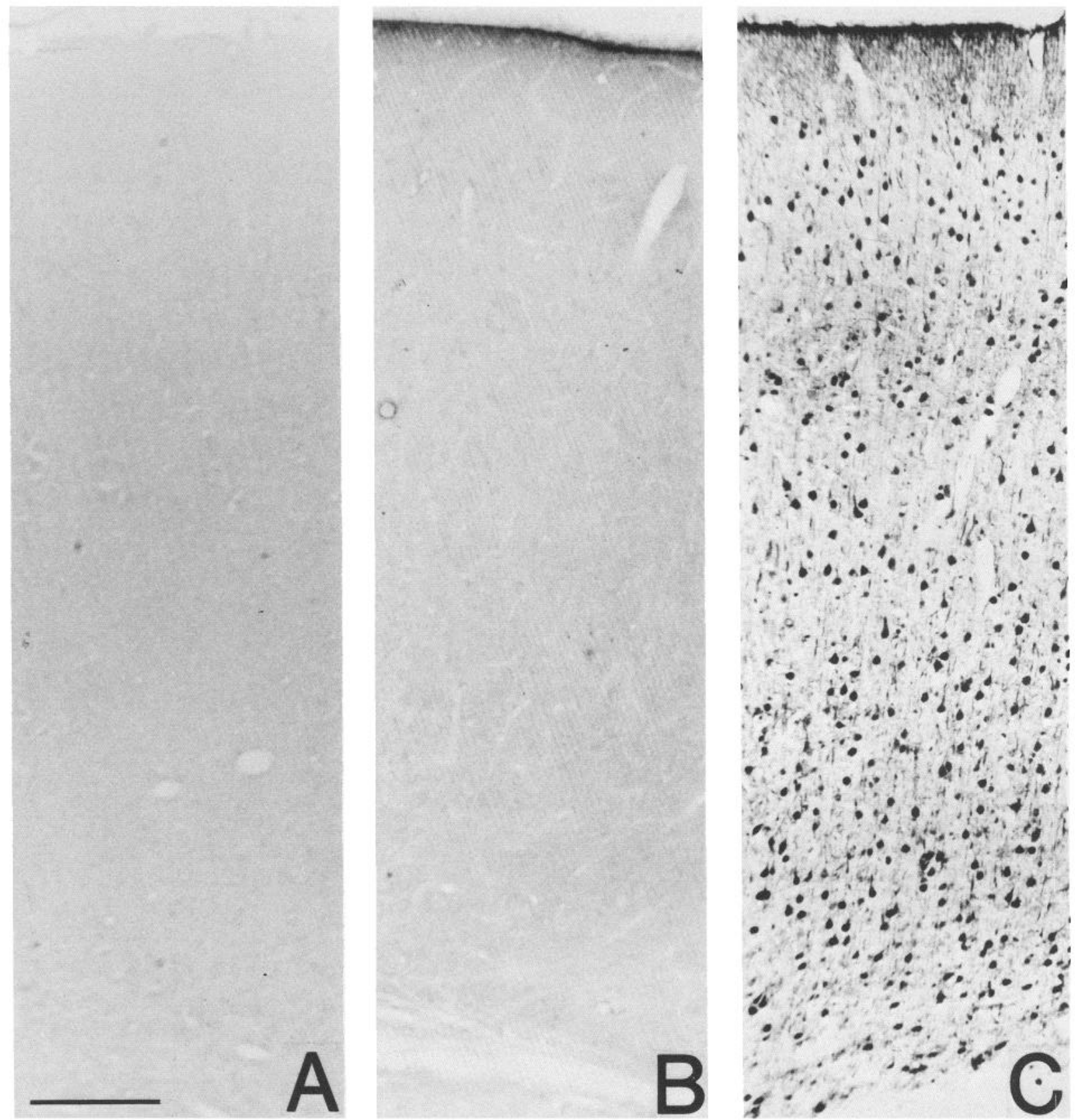

Figure 1. Vibratome sections of rat SI: $A$, Test of method specificity; staining obtained following a complete staining sequence from which the primary antiserum was omitted. $B$, Test of antibody specificity; staining obtained after preabsorbing the primary antiserum with an excess of the antigen (Glu-glutaraldehyde-HC). $C$, Staining following a standard procedure. Calibration bar, $100 \mu \mathrm{m}$.

Staining procedure. The free-floating sections were rinsed 3 times in PBS $(0.01 \mathrm{M}, \mathrm{pH} 7.5)$ and incubated for $15 \mathrm{~min}$ in normal sheep serum (NSS: 2\% in PBS) to mask nonspecific binding sites (Sternberger, 1986). After a quick rinse in PBS, the sections were incubated overnight at $4^{\circ} \mathrm{C}$ in the primary antiserum. On the following day, sections were rinsed in PBS, incubated again in NSS for $15 \mathrm{~min}$, and immersed for $30 \mathrm{~min}$ into the secondary antiserum (sheep antirabbit gamma-globulin; Antibodies, Inc., Davis, CA) diluted 1:100 in NSS. After 3 rinses in PBS, the sections were incubated in rabbit peroxidase-antiperoxidase (PAP) for $30 \mathrm{~min}$. All steps were subsequently repeated according to the modification by Ordronneau et al. (1981) of the double PAP technique (Vacca et al., 1975). This modification allows the use of higher antiserum dilution by intensifying the staining of cell bodies and dendrites. Following the second incubation with PAP, sections were rinsed twice in Tris-buffered saline (TBS: $0.05 \mathrm{M}, \mathrm{pH} 7.6$ ) and incubated in 3,3'-diaminobenzidine (Sigma; $0.075 \%$ in $0.05 \mathrm{M}$ Tris buffer, $\mathrm{pH} 7.6$, or 0.05
$\mathrm{M}$ cacodylate buffer with $0.05 \mathrm{M}$ acetic acid, pH 5.8) and $0.002 \%$ of $3 \%$ $\mathrm{H}_{2} \mathrm{O}_{2}$ for 7-8 min. Sections were rinsed 3 times in TBS, mounted on slides, air-dried, counterstained with cresylecht violet $(0.1 \%)$, and coverslipped with DPX.

Paraffin sections were processed in a similar way, with 3 exceptions: (1) The incubation in primary antiserum was for $48 \mathrm{hr}$ instead of overnight; (2) the incubation in secondary antiserum and in the blocking serum was $10 \mathrm{~min}$ instead of 30 and $15 \mathrm{~min}$; and (3) avidin-biotin complex (Hsu et al., 1981) was used instead of PAP. Paraffin sections immediately adjacent to those reacted for Glu were processed for GABA immunocytochemistry. The protocol was essentially that used for Glu immunocytochemistry, except that the blocking serum used for GABA visualization was normal rabbit serum $(10 \%)$ and the secondary antibody was a biotinylated rabbit anti-rat IgG (Vector) at 1:500. A third adjacent paraffin section was stained with $0.05 \%$ toluidine blue.

Data analysis. Quantitative data on the ratio of immunolabeled ver- 
sus unlabeled neurons were collected from a region of the parietal area of rat brains characterized by the presence of a conspicuous layer IV, with intermingled dysgranular regions, densely packed layers II and III, and a relatively cell-free layer Va. This area corresponds to SI as identified also by Woolsey and LeMessurier (1948), Welker (1971), Zilles et al. (1980), and Donoghue and Wise (1982). Data on the laminar distribution and ratio of Glu-positive neurons were collected only from Vibratome sections under the $40 \times$ objective on a Leitz microscope with a drawing tube. Vibratome sections were selected for this purpose rather than paraflin sections because of greater ease in (1) defining laminar boundaries and (2) recognizing the morphological class-i.e., pyramidal versus nonpyramidal - of stained neurons in $25 \mu \mathrm{m}$ rather than in $4 \mu \mathrm{m}$ sections. Sampled neurons in rats were from $500-\mu \mathrm{m}$-wide sectors of cortex. These sectors were randomly selected in order to have samples from granular and dysgranular fields from SI. ${ }^{1}$ In 5 such sectors all recognizable labeled and unlabeled perikarya were plotted. In 15 other sectors (10 from 2 rats, 293 and 310 , fixed with $4 \%$ paraformaldehyde, and 5 from 2 rats, 394 and 399 , fixed with $4 \%$ carhodiimide), only perikarya displaying an apparently full-size nucleus in the plane of the section were tallied. Sampled neurons in monkeys were from ten 1-mmwide sectors of cortex, randomly selected from 4 cortical blocks. Only perikarya displaying a nucleus were included in the counts. In both rats and monkeys a distinct nucleolus was only rarely observed in labeled neurons. For data on cross-sectional areas, the outlines of perikarya included in the above counts were traced on a data tablet interfaced with a PDP-11 computer.

To test eventual colocalization of Glu and GABA, consecutive paraffin sections from 2 rats $(384,395)$ were examined under the $40 \times$ objective on a Nikon microscope equipped with Nomarski optics. Sampled neurons were taken from a 375- $\mu \mathrm{m}$-wide region from SI. Regions containing convenient landmarks -i.e., capillaries, artifacts, etc.-for the matching of 2 consecutive sections, one reacted with Glu and the other with GABA antibody, were selected. Identification of doublelabeled neurons was possible by superimposing the 2 plotted drawings on the basis of non-neuronal landmarks and by additional verification, at the microscope, of those few elements in which the coexistence of the 2 markers, as judged by the superimposition alone, was equivocal.

\section{Results}

\section{Glu-immunoreactive neurons in rats}

Positive neurons were identified in sections from rats perfused with all fixatives listed. The use of these fixatives did not seem to change significantly the overall pattern of immunostaining. The only obvious differences were the nuclear labeling and higher background staining in material perfused with fixatives containing glutaraldehyde. Also, the administration of colchicine (in 4 out of 24 rats) did not seem to alter the pattern or the number of labeled neurons. Detailed qualitative and quantitative observations were carried out on sections from material fixed without glutaraldehyde. The majority of cortical neurons were either clearly labeled or unlabeled; in the former class, the intensity of labeling was distinctly higher than background staining. These neurons were considered for quantitative data. In a small number of neurons, not exceeding $5 \%$ of those labeled, the level of staining was not sufficiently above background to justify considering them labeled, even though they were not among the clearly unlabeled neurons.

Stained neurons displayed an intense perikaryal granular labeling (Fig. 2, $A, B$ ) continuous with equally intense dendritic labeling (Fig. $2 B$ ). This made it possible, in most cases, to distinguish between pyramidal (Fig. 2, $A, B$ ) and nonpyramidal (Fig. 2, $C, D$ ) labeled neurons. Neurons were considered pyramidal when the apical dendrite was visible (Fig. $2 B$ ); this could be followed for neurons in layers V and VI up to layer II, where

\footnotetext{
${ }^{1}$ Qualitative observations did not reveal conspicuous differences in the density of labeled neurons even when comparing cortex containing barrel fields, as visible in cresylecht violet-stained sections, with cortex outside these fields or granular with dysgranular cortex.
}

it branched. Staining in the neuropil of layer I was likely to be edge artifact or the result of the branching of many apical dendrites of labeled pyramidal neurons. Other criteria could be applied when the apical dendrite was not visible. For instance, the presence of basal dendrites, though not sufficient as such, was judged indicative of a pyramidal neuron if the perikaryon from which the basal dendrites arose, concomitantly, displayed a clear triangular shape. Axons were mostly unlabeled, but their occasional presence could contribute to the identification of a neuron as pyramidal-e.g., if the axon clearly stemmed from the base of a triangular perikaryon (Fig. $2 A$ ). No obvious difference in the pattern or density of labeled neurons was apparent in the sampled regions within SI.

Glu-immunoreactive neurons were present in all cortical layers but were not uniformly distributed. In all sections, labeled neurons were most numerous in layers II-III and V-VI (Fig. $3 A$ ) and were, for the most part, identifiable as pyramidal (Fig. $3, B, D)$. Nonpyramidal neurons were also present and represented the majority of labeled neurons in layer IV (Fig. 3C). Quantitative data were collected from 15 randomly selected $500-\mu \mathrm{m}$-wide sectors (as described in Materials and Methods) from rats 291, 310,394, and 399. The counts and percentage of neurons (displaying the nucleus in the plane of the section, see Materials and Methods) in these samples are shown in Table 2. Of the 961 neurons in the total sample, 377 were Glu-positive $(39 \%)$. Very few neurons $(<5 \%)$ were stained in layer I. In layers II and III, 33\% (SD, 11.6; SE, 2.9) and 32\% (SD, 5.7; SE, 1.4) were Glu-positive, respectively. Labeled pyramidal neurons constituted $84 \%$ in layer II and $94 \%$ in layer III. In layer IV the percentage of immunoreactive neurons was $13 \%(\mathrm{SD}, 5.4 ; \mathrm{SE}$, $1.4) ; 74 \%$ of these were nonpyramidal. Layer $V$ had the highest percentage of positive neurons: $36 \%$ (SD, $7.3 ; \mathrm{SE}, 1.8)$. In this layer, $97 \%$ of positive neurons were pyramidal, and only $3 \%$ were classified as nonpyramidal. In layer VI, neurons stained by the anti-Glu serum were $29 \%$ (SD, 6.0; SE, 1.5); of these, $32 \%$ were identified as nonpyramidal. Examples of the distribution of neurons considered for the counts are shown in Figure 4.

Measurements of cross-sectional areas of the same neurons sampled in Table 2 are shown in Figure 5. Glu-positive neurons in layers II and III had a mean cross-sectional area of $159 \mu \mathrm{m}^{2}$ (SD, 36) and $168 \mu \mathrm{m}^{2}$ (SD, 54), respectively. Layer IV Glupositive neurons were smaller-i.e., with cross-sectional areas of $96 \mu \mathrm{m}^{2}$ (SD, 26). Glu-positive neurons in layer $V$ had the largest cross-sectional area-i.e., $222 \mu \mathrm{m}^{2}$ (SD, 82)-and among these were the largest Glu-positive neurons observed, with crosssectional areas about $480 \mu \mathrm{m}^{2}$. Small Glu-positive neurons were also observed in the same layer-i.e., neurons with cross-sectional areas $<100 \mu \mathrm{m}^{2}$. Layer VI Glu-positive neurons had a mean area of $152 \mu \mathrm{m}^{2}$ (SD, 52). Glu-positive dotlike elements (Fig. 2A) were present throughout all layers of the cortex but most densely in lower layer III/upper layer IV and in lower layer V/upper layer VI (Fig. 1C). Because of their uniform size, it is likely that these elements correspond to terminal boutons rather than dendrites cut across (see also Discussion).

\section{Comparison of Glu- and GABA-immunoreactive neurons in rats}

The amino acid GABA is also known to be a neurotransmitter for many cortical neurons (Houser et al., 1984). GABA is synthesized from Glu by glutamic acid decarboxylase (GAD) and is transaminated to succinic semi-aldehyde by GABA trans- 

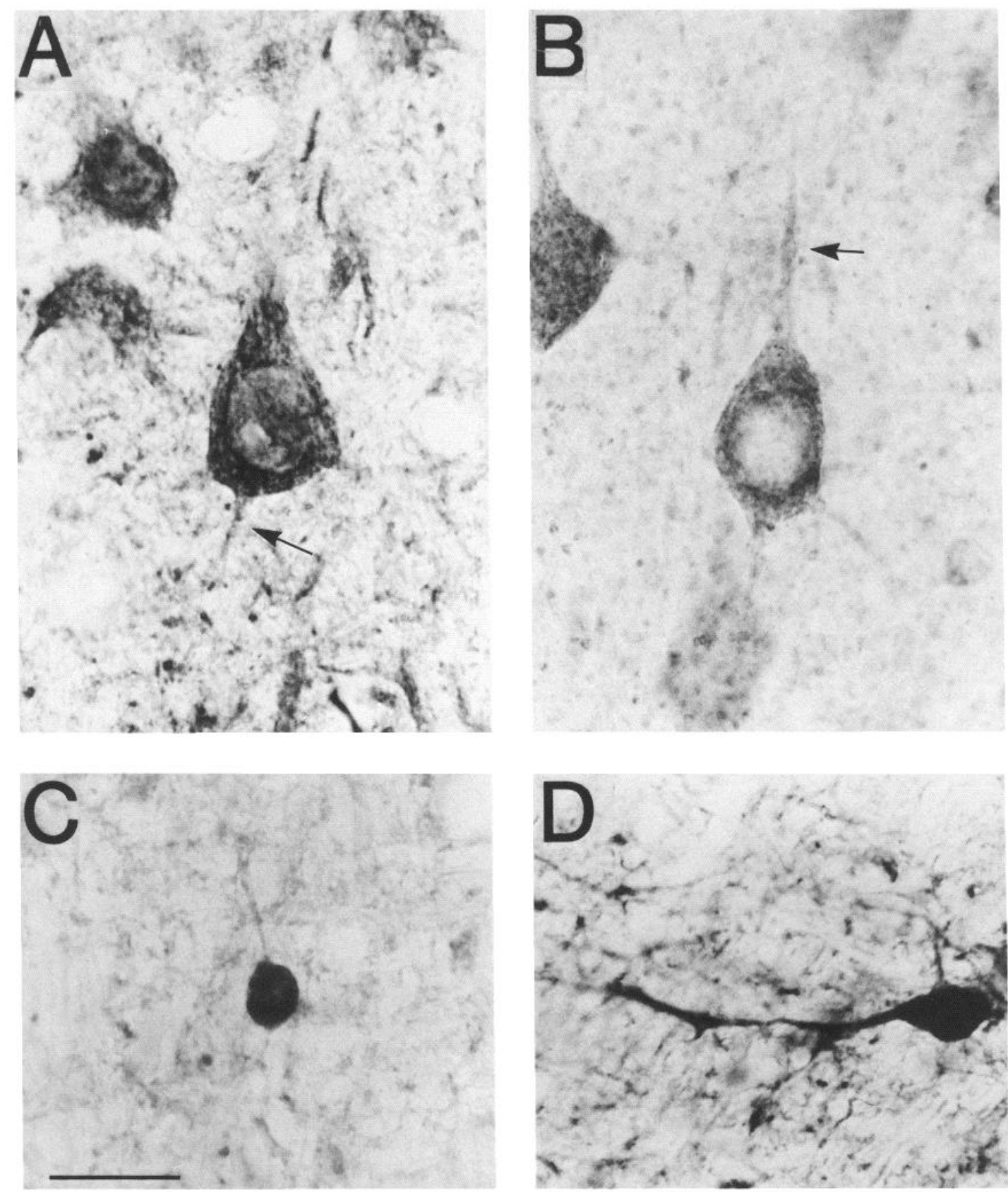

Figure 2. Photomicrographs of Glu-immunoreactive cells from the SI of rats. $A$ and $B$, Two large neurons in layers V and III, respectively, that were classified as pyramidal in the present counts. In both neurons the nucleus is visible and relatively unstained. In $A$, the $a r r o w$ points at what is probably an initial segment of an axon; in $B$, arrow points at a partly filled apical dendrite. $C$ and $D$, Two examples of neurons classified here as nonpyramidal; the neuron in $C$ is from layer IV and may be of the bipolar type, while the best impregnated dendrite in the neuron in $D$, from layer VI, is parallel to the pial surface. Calibration bar, $20 \mu \mathrm{m}$.

aminase (GABA-T) in the presence of $\alpha$-ketoglutarate, which is then converted back to Glu by GABA-T. Therefore, the question arises whether some labeled neurons in the present material may actually be GABAergic and contain high levels of Glu as precursor and/or metabolite. Ottersen and Storm-Mathisen's (1984a) and our own observations from the same brains used for this study that some Purkinje cells and neurons of the nucleus reticularis thalami were stained by Glu immunocytochemistry suggest that this might be the case. Double-labeling experiments were performed using Glu and GABA antisera on thin adjacent paraffin sections (see Materials and Methods). In these sections, Glu-positive neurons represented $36 \%$ of all cortical neurons, and their pattern of distribution was similar to that reported above for Vibratome sections. GABA-positive neurons were also present throughout the cortex and represented $31 \%$ of all cortical neurons; no apparent laminar segregation of these neurons was observed (see also Ottersen and Storm-Mathisen, 1984b; Seguela et al., 1984; and J. M. Lauder et al., personal communication). Single-labeled Glu-positive neurons had a perikaryal cross-sectional area twice as large as that of single-labeled 
Figure 3. A, Camera lucida drawing of the distribution of labeled and unlabeled neurons in one vertical strip from a section of the rat SI processed for Glu immunocytochemistry and counterstained with cresylecht violet. Neurons were charted regardless of whether they displayed a nucleus in the plane of the section. Calibration bar, $100 \mu \mathrm{m}$. $B-D$, Drawings of some representative neurons from different layers of the same strip of cortex. Calibration bar, $10 \mu \mathrm{m}$.
A

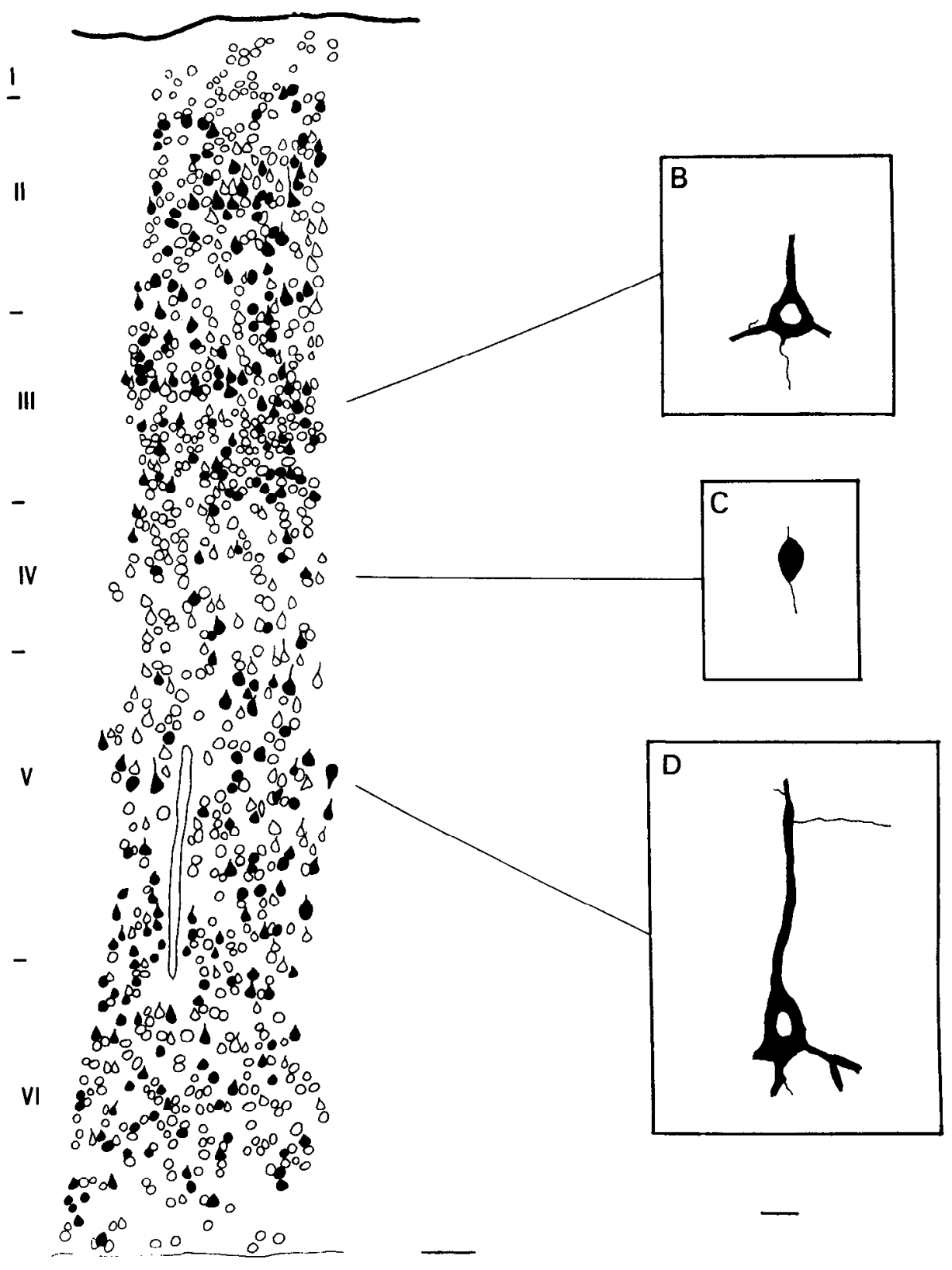

GABA-positive neurons (Fig. 6). Layer I was not included in the present counts because, although it contained GABA-positive neurons, it contained hardly any Glu-positive perikaryal in the thin sections used for the purpose of double-labeling. The results of double-labeling experiments are summarized in Table 3. Of the 760 neurons studied in thin paraffin sections, 387 stained positively for Glu (51\%), 332 were labeled by the antiGABA serum (44\%), and 41 were positive for both Glu and GABA $(5 \%)$. The neurons positive for both amino acids amounted to $10 \%$ of the Glu-positive neurons. In layers II and III the mean percentage of such neurons was $10 \%$ (SD, 7.5$)$ and $11 \%(\mathrm{SD}, 4.0)$, respectively. In layer IV $12 \%(\mathrm{SD}, 7.3)$ of Glupositive neurons were also GABA-positive. In layer $\mathrm{V}, 10 \%$ (SD, 7.7) of Glu neurons also stained positively for GABA, while in layer VI their ratio was $5 \%$ (SD, 3.8). Examples of the distribution of neurons considered for the counts are shown in Figure 7. Perikaryal cross-sectional areas of neurons that stained for both Glu and GABA were also measured. The mean area of Glu/GABA neurons in layers II and III was 140 (SD, 59) and 127 (SD, 45), respectively; in layer IV, it was 176 (SD, 99), and in layers V and VI, 130 (SD, 88) and 107 (SD, 64), respectively. Mean perikaryal area of Glu/GABA neurons was in the range of the largest among GABA-positive neurons.

\section{Glu-immunoreactive neurons in monkeys}

The qualitative observations with Glu antiserum and criteria for identification of neurons reported above for rats are valid for the monkey cortex as well. In the 2 monkeys (M94 and M96), perfused with different fixatives, the distribution of Glupositive neurons was identical. As in rats, the higher percentages of labeled neurons were in layers III and V, and the lowest in layer IV; most labeled neurons were pyramidal (Fig. 8). Perccntages of labeled neurons in Table 4 are given for each subdivision of SI in monkeys-i.e., 3a, 3b, 1, and 2. Glu-positive 
A
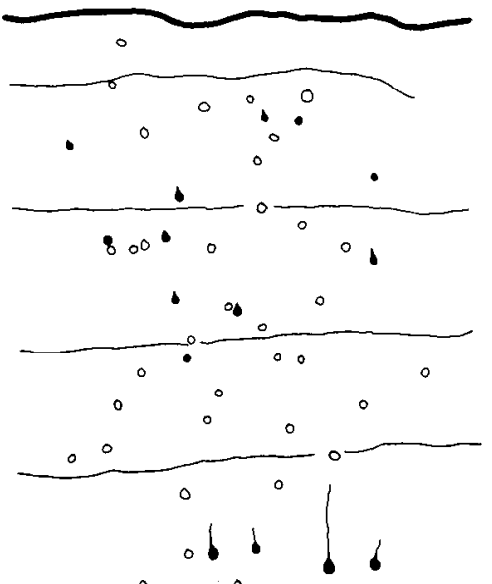$$
0
$$

0
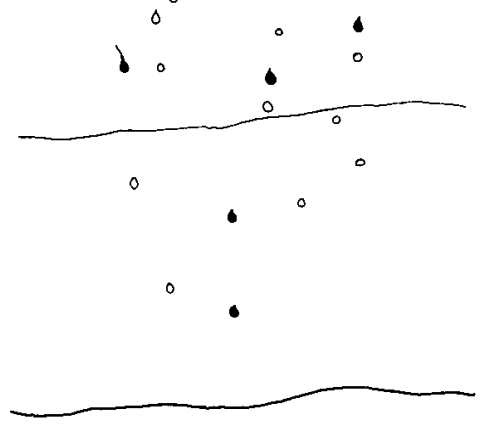

C

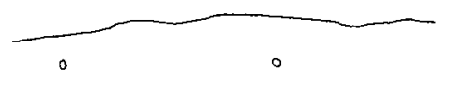

6

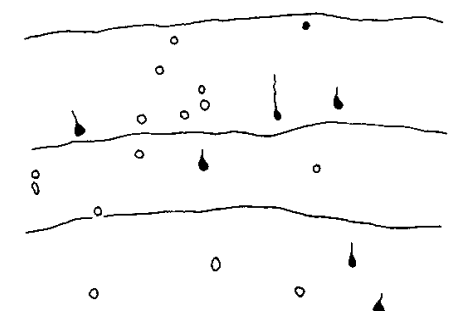

$\circ$

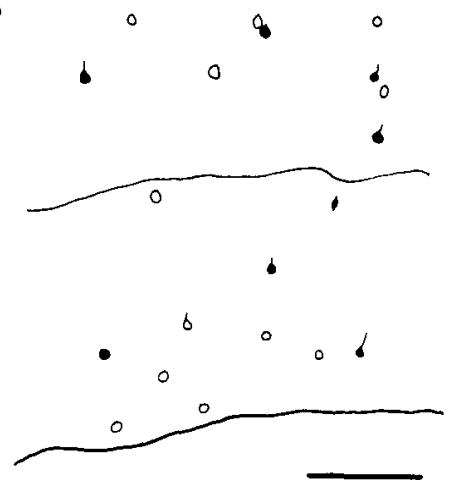

B

I

II

III

IV
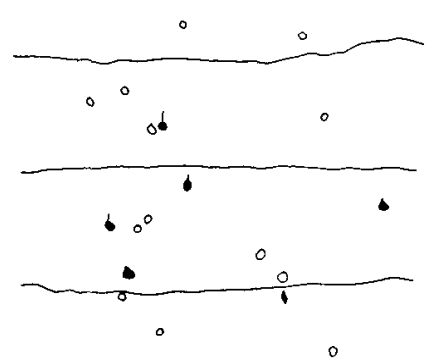

V
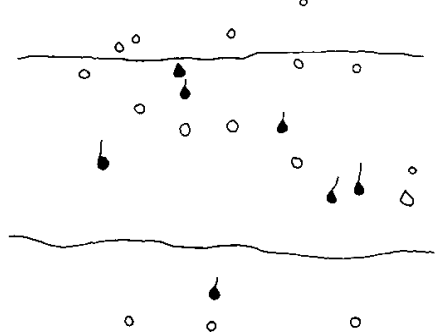

VI

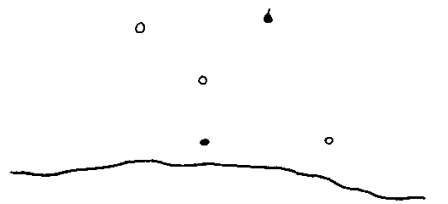

D

I

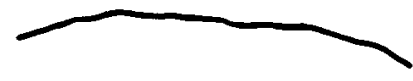

II

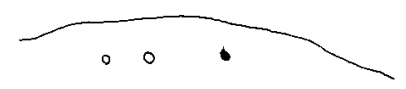

III

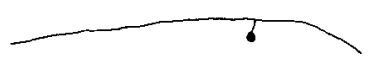

IV

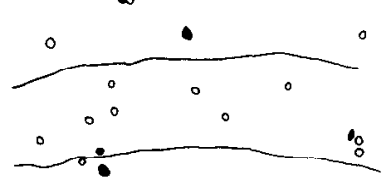

v

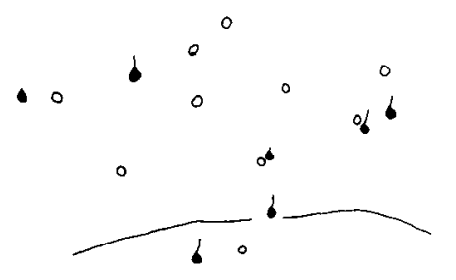

VI

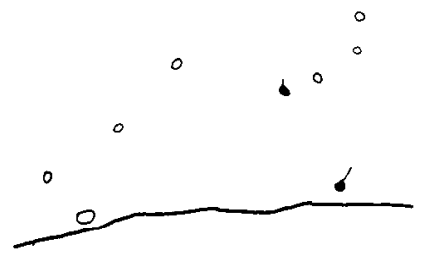

Figure 4. Examples of reconstruction of labeled and unlabeled neurons from 2 strips of cortex from rats perfused with $4 \%$ paraformaldehyde $(A$ and $B)$ and from 2 strips of cortex from rats perfused with $4 \%$ carbodiimide $(C$ and $D$ ). Only neurons with a nucleus in the plane of the section are represented. Calibration bar, $200 \mu \mathrm{m}$. 
Table 2. Percentages of Glu-immunoreactive neurons (L) versus unlabeled (LL) neurons in counts from 15 sections (25 $\mu \mathrm{m}$ thick) from 4 rats ${ }^{a}$

\begin{tabular}{|c|c|c|c|c|c|c|c|c|c|c|c|c|}
\hline \multirow[b]{2}{*}{ Rat } & \multicolumn{2}{|l|}{ I } & \multicolumn{2}{|l|}{ II } & \multicolumn{2}{|l|}{$\underline{\text { III }}$} & \multicolumn{2}{|l|}{ IV } & \multicolumn{2}{|l|}{ V } & \multicolumn{2}{|l|}{ VI } \\
\hline & $\mathrm{L} / \mathrm{UL}$ & $\%$ & $\mathrm{~L} / \mathrm{UL}$ & $\%$ & $\mathrm{~L} / \mathrm{UL}$ & $\%$ & L/UL & $\%$ & $\mathrm{~L} / \mathrm{UL}$ & $\%$ & L/UL & $\%$ \\
\hline 291 & $0 / 2$ & - & $8 / 24$ & 25 & $6 / 13$ & 32 & $1 / 8$ & 11 & $7 / 23$ & 23 & $8 / 17$ & 32 \\
\hline 291 & $0 / 1$ & - & $8 / 18$ & 30 & $8 / 20$ & 29 & $2 / 16$ & 11 & $14 / 28$ & 33 & $6 / 17$ & 26 \\
\hline 291 & $1 / 7$ & 13 & $10 / 6$ & 63 & $12 / 26$ & 32 & $4 / 21$ & 16 & $12 / 30$ & 42 & $5 / 16$ & 24 \\
\hline 291 & $0 / 3$ & - & $5 / 17$ & 23 & $9 / 14$ & 39 & $3 / 17$ & 15 & $14 / 32$ & 46 & $5 / 11$ & 31 \\
\hline 291 & $0 / 4$ & - & $4 / 14$ & 22 & $9 / 16$ & 36 & $3 / 15$ & 17 & $9 / 17$ & 35 & $4 / 11$ & 27 \\
\hline 310 & $0 / 5$ & - & $6 / 12$ & 33 & $8 / 22$ & 27 & $2 / 14$ & 13 & $11 / 23$ & 32 & $6 / 15$ & 29 \\
\hline 310 & $0 / 1$ & - & $5 / 12$ & 29 & $5 / 15$ & 25 & $1 / 12$ & 8 & $7 / 19$ & 26 & $2 / 7$ & 22 \\
\hline 310 & $0 / 3$ & - & $5 / 8$ & 38 & $5 / 14$ & 26 & $0 / 7$ & 0 & $11 / 19$ & 37 & $3 / 10$ & 23 \\
\hline 310 & $0 / 1$ & - & $1 / 5$ & 17 & $4 / 8$ & 33 & $1 / 8$ & 11 & $6 / 15$ & 29 & $3 / 9$ & 25 \\
\hline 310 & $0 / 2$ & - & $3 / 9$ & 25 & $2 / 5$ & 29 & $1 / 9$ & 10 & $4 / 8$ & 33 & $3 / 9$ & 25 \\
\hline 394 & $0 / 3$ & - & $4 / 7$ & 36 & $6 / 11$ & 35 & $3 / 11$ & 21 & $5 / 6$ & 45 & $6 / 9$ & 40 \\
\hline 394 & $0 / 0$ & - & $1 / 2$ & 33 & $4 / 5$ & 44 & $1 / 5$ & 17 & $6 / 9$ & 40 & $4 / 7$ & 36 \\
\hline 394 & $0 / 1$ & - & $1 / 1$ & 50 & $3 / 7$ & 30 & $2 / 7$ & 22 & $10 / 14$ & 41 & $3 / 7$ & 30 \\
\hline 399 & $1 / 2$ & 33 & $3 / 4$ & 42 & $3 / 10$ & 23 & $2 / 10$ & 17 & $3 / 8$ & $27^{*}$ & $3 / 8$ & 27 \\
\hline 399 & $0 / 0$ & - & $3 / 6$ & 30 & $3 / 5$ & 38 & $1 / 7$ & 13 & $8 / 10$ & 42 & $5 / 7$ & 41 \\
\hline \multicolumn{3}{|c|}{ Mean (SD/SE) } & \multicolumn{2}{|c|}{$33(11.6 / 2.9)$} & \multicolumn{2}{|c|}{$31.8(5.7 / 1.4)$} & \multicolumn{2}{|c|}{$13.4(5.4 / 1.4)$} & \multicolumn{2}{|c|}{$35.5(7.3 / 1.8)$} & \multicolumn{2}{|c|}{$29.2(6.0 / 1.5)$} \\
\hline
\end{tabular}

${ }^{a}$ Only cells displaying a full-size nucleus in the plane of the section were tallied.

neurons in layers II and III had mean cross-sectional areas of 149 (SD, 48) and $186 \mu \mathrm{m}^{2}$ (SD, 49), respectively; the same neurons in layers IV, V, and VI had mean cross-sectional areas of 175 (SD, 89), 211 (SD, 102), and $160 \mu \mathrm{m}^{2}$ (SD, 51), respectively.

\section{Discussion}

The first and most important issue to be addressed is the presence of Glu in all neurons, where it is necessary for the cellular metabolism. On the basis of observation of sections from brains of glutaraldehyde-perfused mice and rats processed for Glu immunocytochemistry, Ottersen and Storm-Mathisen (1984a) suggested their results could be accounted for largely by increased metabolic activity in labeled neurons. While the same conclusion may be derived from the present results, it should be pointed out that several features differentiate Ottersen and StormMathisen's study from ours. The antibodies used in the 2 studies, though produced with similar techniques, may differ in their specificity. Observations on CNS regions other than cortex from the brains used for the present study reveal that the distribution of the Glu-positive ncurons closely matches that of neurons with "high Glu-LI levels" in Ottersen and Storm-Mathisen's study; some differences are observed, however. For instance, intensely stained neurons in the medial habenula, inferior olive, and substantia gelatinosa (Weinberg et al., 1987) observed with this antiserum were not reported by Ottersen and Storm-Mathisen (1984a, b). Also, fixatives containing glutaraldehyde, the only kind employed by Ottersen and Storm-Mathisen, give a higher background than those used here. ${ }^{2}$ Although no techniques are available to resolve the issue of whether Glu is metabolic or exists in a neurotransmitter pool, some evidence supports the hypothesis that the Glu immunoreactivity observed in the present study reflects a high concentration of this amino acid related to neurotransmission. The fact that the staining is present in about one-third of all cortical neurons reflects remarkable selectivity. This selectivity may be related to the neurotransmitter pool of Glu, which is synthesized at a higher rate than the metabolic pool of Glu (Storm-Mathisen and Ottersen, 1986); it is conceivable that hypoxia during perfusion depletes the latter, leaving the former relatively unaffected. Furthermore, it is unlikely that our results are related to higher metabolic activity in labeled than in unlabeled neurons, because of the lack of correlation between the distribution of Glu as revealed in the present experiments and the pattern of labeling observed using the histochemical visualization of cytochrome oxidase (Wong-Riley, 1979). In some experiments, not reported in Results, it was

\footnotetext{
${ }^{2}$ The use of different fixatives did not seem to change the specificity of the staining, as shown by the observation that, in sections from animals perfused without glutaraldehyde, staining was abolished when the antiserum was incubated overnight with the conjugate (Glu-glutaraldehyde-HC).
}

Table 3. Percentages of Glu-positive, GABA-positive, and Glu/GABA-positive neurons in counts from 8 sections (4 $\mu \mathrm{m}$ thick)

\begin{tabular}{|c|c|c|c|c|c|c|c|c|c|c|c|c|c|c|c|c|}
\hline \multirow[b]{2}{*}{ Rat } & \multicolumn{3}{|l|}{ II } & \multicolumn{3}{|l|}{ III } & \multicolumn{3}{|l|}{ IV } & \multicolumn{3}{|l|}{ V } & \multicolumn{3}{|l|}{ VI } & \multirow{2}{*}{$\begin{array}{l}\text { Total } \\
\text { Glu/ } \\
\text { GABA } \\
(\%)\end{array}$} \\
\hline & Glu & GABA & $\begin{array}{l}\text { Glu/ } \\
\text { GABA }\end{array}$ & Glu & GABA & $\begin{array}{l}\text { Glu/ } \\
\text { GABA }\end{array}$ & Glu & GABA & $\begin{array}{l}\text { Glu/ } \\
\text { GABA }\end{array}$ & Glu & GABA & $\begin{array}{l}\text { Glu/ } \\
\text { GABA }\end{array}$ & Glu & GABA & $\begin{array}{l}\text { Glu/ } \\
\text { GABA }\end{array}$ & \\
\hline 384 & 21 & 11 & 3 & 22 & 15 & 2 & 19 & 19 & 3 & 18 & 19 & 4 & 19 & 20 & 0 & 6 \\
\hline 384 & 19 & 25 & 4 & 21 & 24 & 3 & 24 & 38 & 2 & 29 & 39 & 3 & 32 & 32 & 2 & 5 \\
\hline 395 & 14 & 9 & 0 & 15 & 21 & 1 & 19 & 16 & 1 & 13 & 10 & 2 & 10 & 9 & 1 & 4 \\
\hline 395 & 16 & 12 & 1 & 23 & 14 & 4 & 15 & 11 & 4 & 22 & 15 & 0 & 16 & 14 & 1 & 6 \\
\hline
\end{tabular}


found that histochemistry of this enzyme produces two patterns of staining in SI of rats: one in the neuropil (presumably related to axon terminals), and one revealing cell bodies. Although most neurons labeled by cytochrome oxidase are in infragranular layers, only scattered cells are present in layers II and III. Carroll and Wong-Riley (1985) correlated the presence of cytochrome oxidase-positive neurons $(\mathrm{CO}+)$ with that of neurons labeled following local injections of ${ }^{3} \mathrm{H}$-Glu and ${ }^{3} \mathrm{H}$-Asp in the visual cortex of squirrel monkeys and found that $\mathrm{CO}+/ \mathrm{Glu}$ (or Asp) + neurons were larger than $\mathrm{CO}+/ \mathrm{Glu}$ (or Asp) - neurons, thus suggesting that $\mathrm{CO}$ staining was correlated more to neuronal size than to the presence of Glu (or Asp). Selectivity in the distribution of possible labeled terminals has also been observed in the present material. An EM investigation of such elements at spinal cord levels has shown that synaptic endings are labeled by the same antiserum employed here and that these may belong to a distinct morphological class (van Eyck et al., 1986; Weinberg et al., 1987).

Second, Glu-positive neurons may be actually GABAergic and labeling reflect the close metabolic relationship between these 2 amino acids even though characterization of our antiGlu serum has provided convincing evidence that the antiserum does not cross-react with GABA (Hepler et al., 1986, 1987). Reports to date indicate that only nonpyramidal neurons are GABAergic (Ribak, 1978; Emson and Hunt, 1981; Hendry and Jones, 1981; Houser et al., 1983). However, since some Glupositive neurons are nonpyramidal, the possibility of colocalization needs to be considered. This question was addressed directly by the double-labeling experiments. These show that only a fraction of Glu-positive neurons are also labeled by the GABA antiserum $(<10 \%)$. These may be GABAergic neurons in which Glu levels are high as a result of lowered GAD activity, as determined by metabolic factors. On the same basis, one may account for the higher percentage of GABA neurons compared to GAD neurons in the cat striate cortex (Fitzpatrick et al., 1983; Gabbott and Somogyi, 1986).

A third important issue concerns the penetration of the antibodies in thick $(25 \mu \mathrm{m})$ sections and possible sampling bias resulting from it. For this reason, quantitative data from these sections were gathered, including only neurons displaying a fullsize nucleus in the plane of the section. Counts on thin $(4 \mu \mathrm{m})$ paraffin sections gave percentages of labeled versus unlabeled neurons identical to those from thicker sections.

Donoghue et al. (1985) recently studied the distribution of glutaminase (GLN) immunoreactivity in neurons of the somatic sensory cortex of rats, guinea pigs, and monkeys. They report that, in all 3 species, layers V and VI contain a high (unspecified) number of GLN-positive neurons. Layers II and III contain

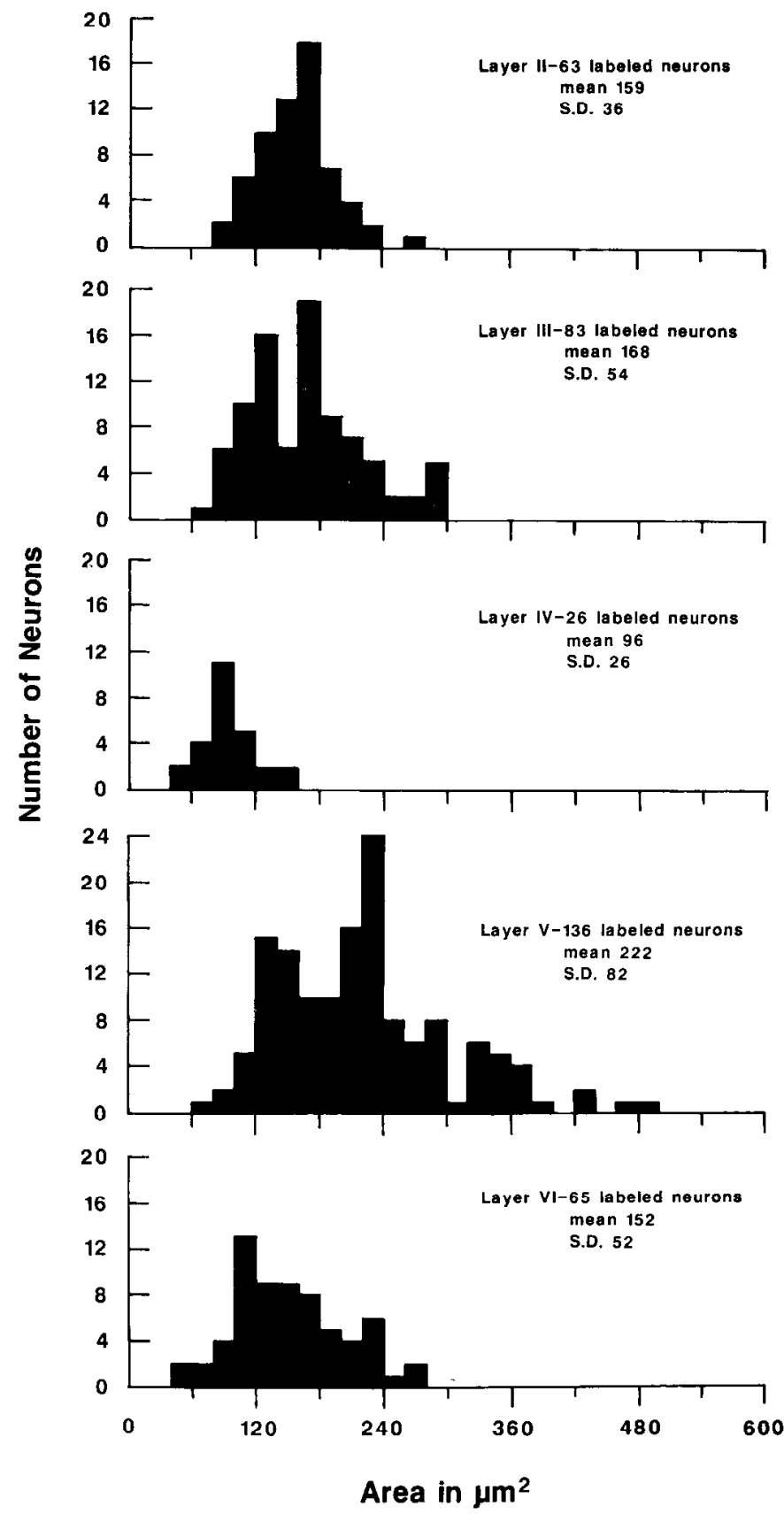

Figure 5. Histograms of the size and number of Glu-immunoreactive neurons in layers II through VI. Data were collected from 10 randomly selected strips from Vibratome sections through SI of rats.

Table 4. Percentage of Glu-immunoreactive neurons (L) versus unlabeled neurons (UL) in counts from 10 sections (25 $\mu \mathrm{m}$ thick) from monkeys M94 and M96

\begin{tabular}{|c|c|c|c|c|c|c|c|c|c|c|}
\hline \multirow[b]{2}{*}{ Area } & \multicolumn{2}{|l|}{ II } & \multicolumn{2}{|l|}{ III } & \multicolumn{2}{|l|}{ IV } & \multicolumn{2}{|l|}{ V } & \multicolumn{2}{|l|}{ VI } \\
\hline & $\mathrm{L} / \mathrm{UL}$ & $\%$ & $\mathrm{~L} / \mathrm{UL}$ & $\%$ & L/UL & $\%$ & $\mathrm{~L} / \mathrm{UL}$ & $\%$ & $\mathrm{~L} / \mathrm{UL}$ & $\%$ \\
\hline $3 a$ & $14 / 25$ & 35 & $22 / 21$ & 51 & $2 / 13$ & 13 & $11 / 12$ & 48 & $6 / 7$ & 46 \\
\hline $3 b$ & $13 / 23$ & 36 & $12 / 12$ & 50 & $7 / 24$ & 22 & $10 / 10$ & 50 & $3 / 6$ & 33 \\
\hline 1 & $32 / 43$ & 42 & $33 / 37$ & 47 & $5 / 19$ & 20 & $25 / 22$ & 53 & $9 / 13$ & 40 \\
\hline 2 & $21 / 25$ & 45 & $25 / 29$ & 46 & $5 / 20$ & 20 & $17 / 14$ & 54 & $7 / 11$ & 39 \\
\hline Total & $80 / 158$ & 40 & $92 / 99$ & 49 & $19 / 76$ & 19 & $63 / 58$ & 51 & $25 / 37$ & 40 \\
\hline
\end{tabular}




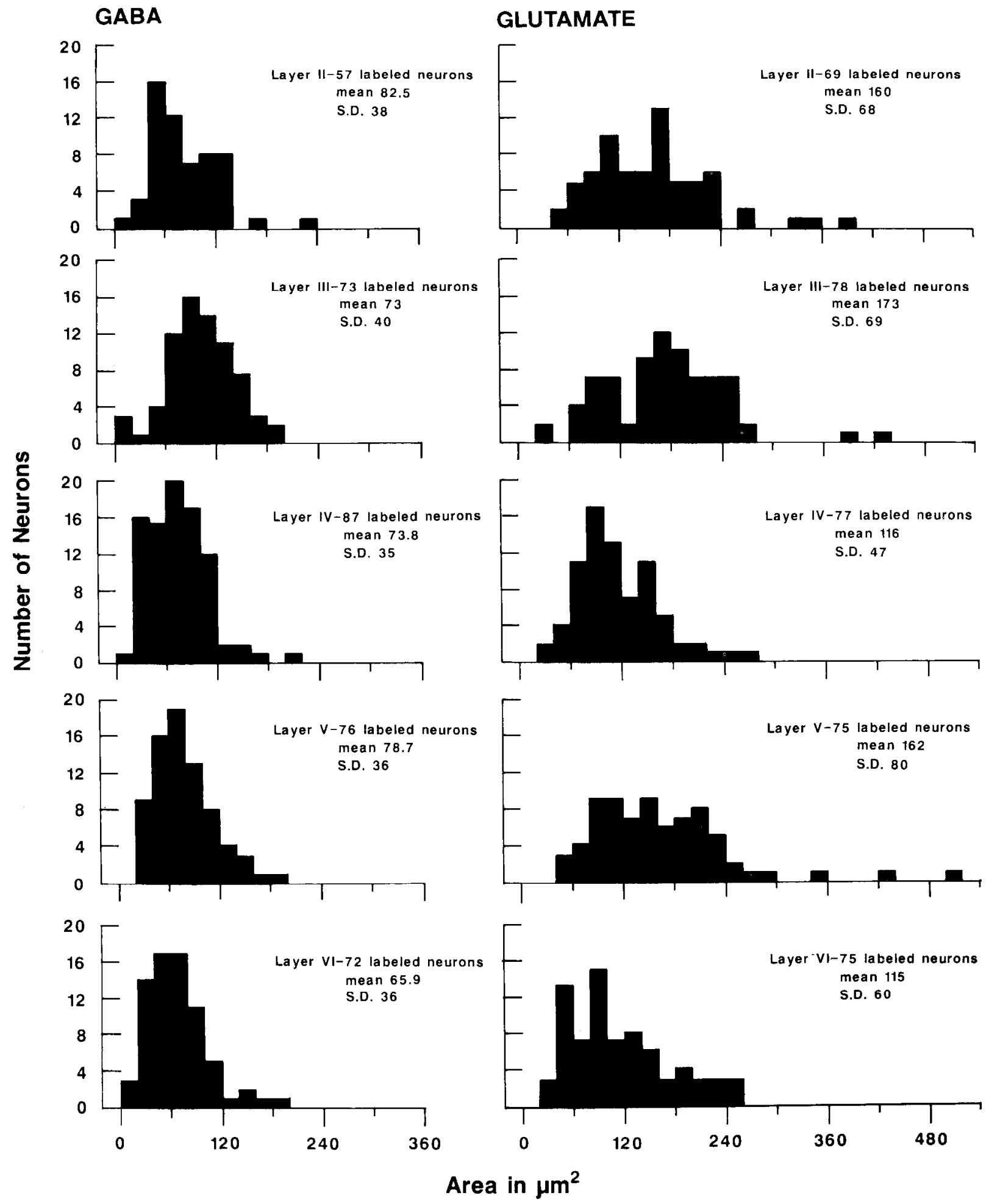

Figure 6. Histograms of the size and number of Glu- and GABA-immunoreactive neurons. Data were collected from 4 randomly selected strips from paraffin sections through SI of rats. Glu-immunoreactive neurons have, on the whole, perikarya twice as large as GABA-immunoreactive neurons.

only a few GLN-positive neurons in rats and guinea pigs; in monkeys, the number of GLN-positive neurons in the same layers varies in different cytoarchitectonic areas. The present results in rats are in apparent disagreement with those of Donoghue et al., since Glu-positive neurons are about as numerous in layers II and III as in infragranular layers. Also, in monkeys, layers II and III contain numerous Glu-positive neurons (35-
47 and $46-53 \%$, respectively), and no conspicuous differences are seen on comparing the relative number of Glu-positive neurons in areas $3 a, 3 b, 1$, and 2 . An explanation for the discrepancy between the present results and those of Donoghue et al. may be that Glu is synthesized by way of more than a single enzymatic pathway (e.g., from ornithine: Roberts, 1981; McGeer et al., 1983). On this ground, it is not surprising that 2 (or more) 

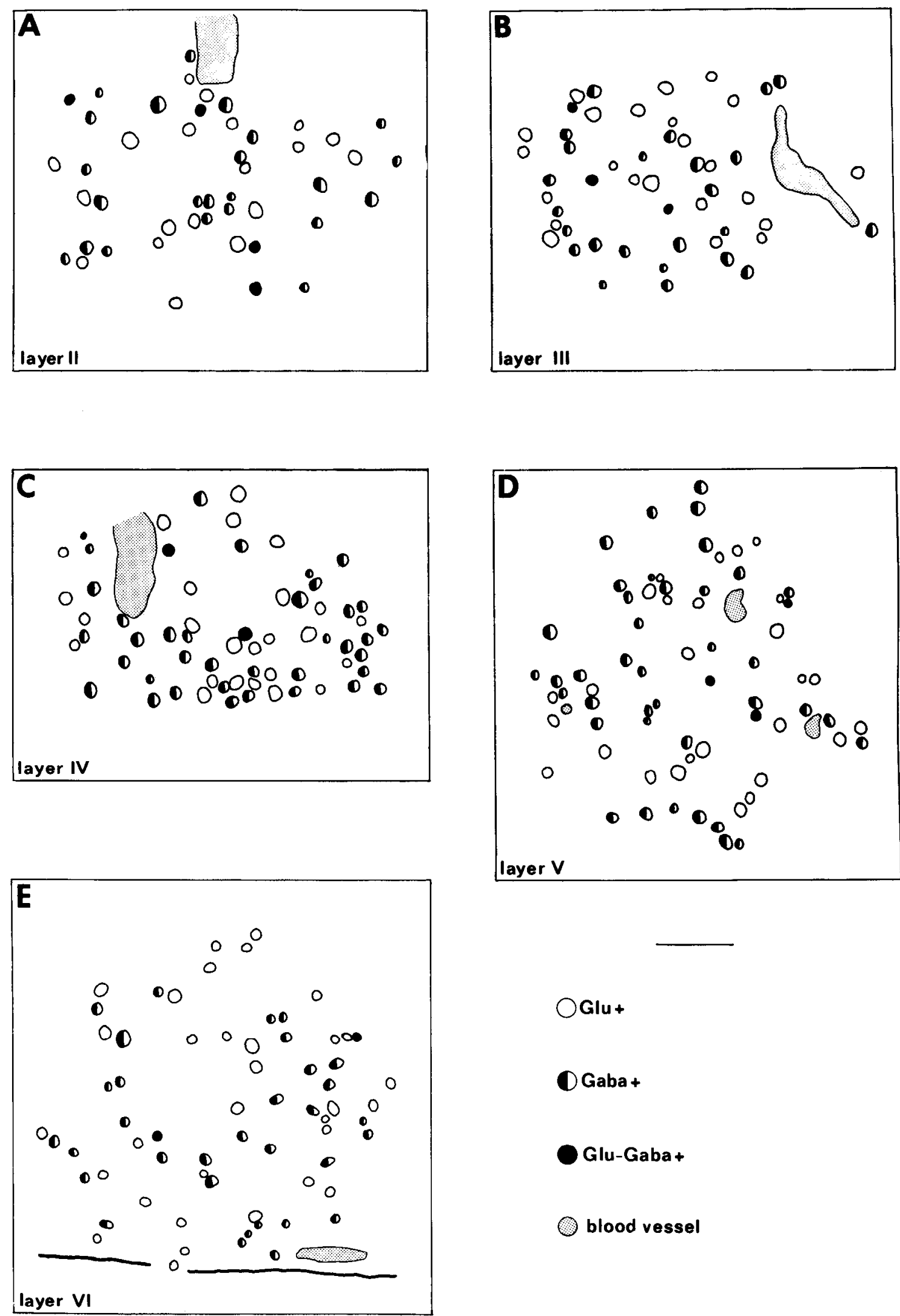

OGlu+

Gaba +

Glu-Gaba +

blood ressel

Figure 7. Camera lucida drawing of the distribution of Glu- and GABA-immunoreactive neurons and of neurons positive for both amino acids as revealed in single thin paraffin section from the rat SI. Calibration bar, $75 \mu \mathrm{m}$. 
area $3 \mathbf{a}$

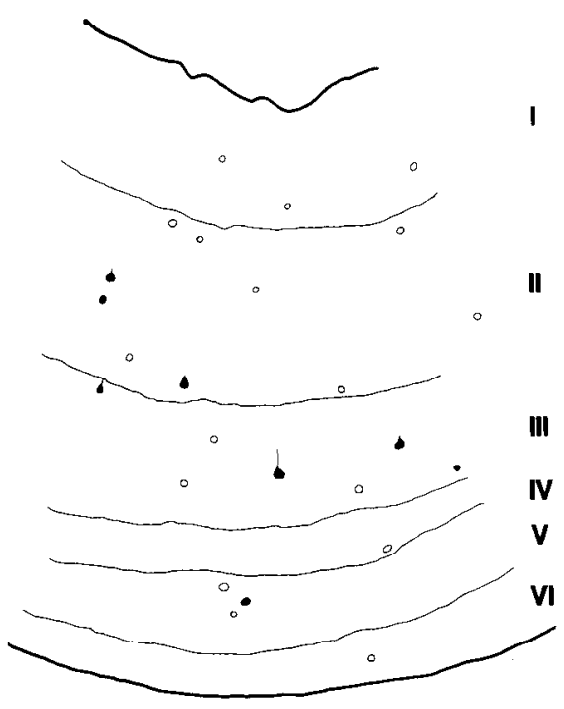

area 1
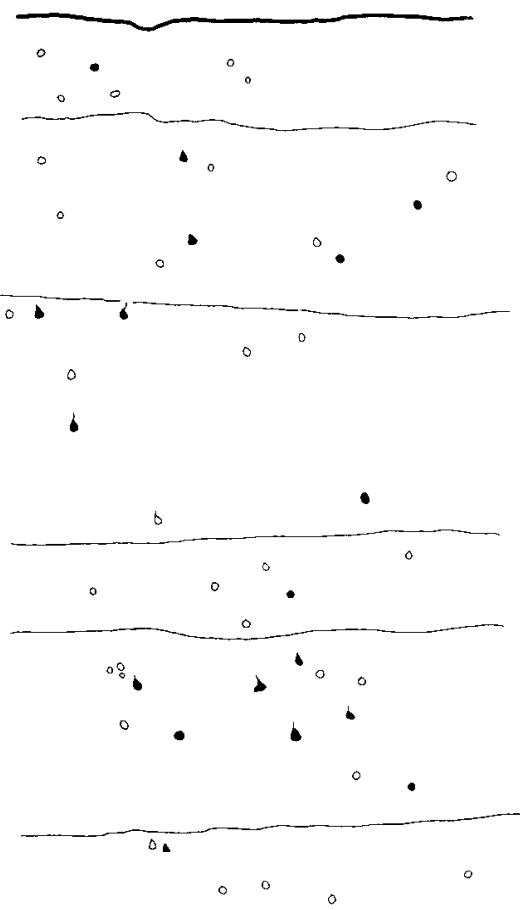

Figure 8. Camera lucida drawings of the distribution of labeled versus unlabeled neurons in areas $3 a, 3 b, 1$, and 2 of the monkey SI. Only neurons with a nucleus in the plane of the section are represented. Calibration bar, $200 \mu \mathrm{m}$. area $3 b$
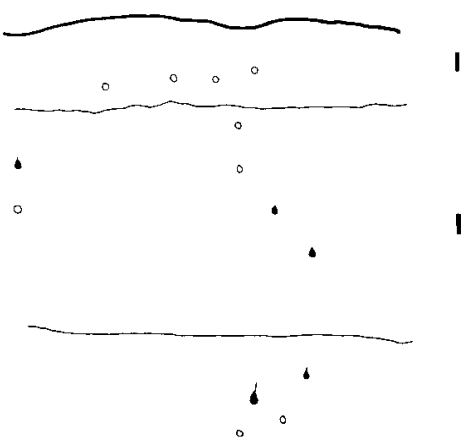

III
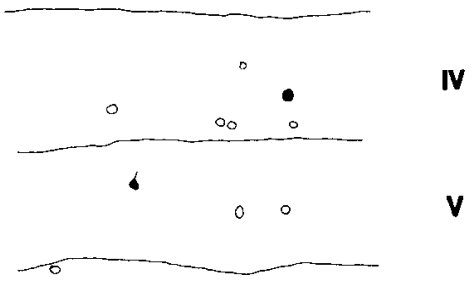

V

area 2

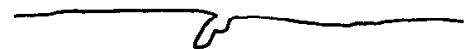

I

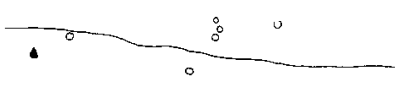

11

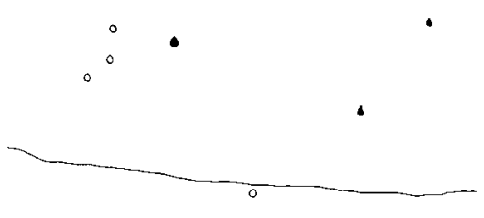

III

- 8

W

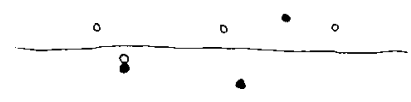

V

v

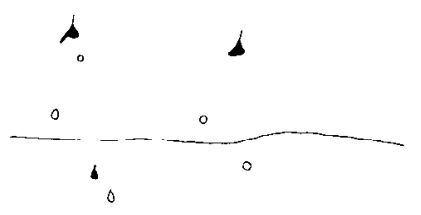


Glu-positive populations exist in the cerebral cortex: One, mainly present in layers $\mathrm{V}$ and VI, may utilize glutamine as substrate and contain elevated concentrations of GLN; the second one, mainly in layers II and III, may use other enzyme(s) and stain only for a Glu antiserum. An analogy can be made between these data and those obtained in the dorsal root ganglia, in which GLN-positive neurons represent a fraction of all neurons stained by the same anti-Glu serum as was used in this study (Battaglia et al., 1986).

The present evidence in favor of glutamergic cortical neurons is supported by a vast literature on this subject (e.g., Watkins and Evans, 1981; Fagg and Foster, 1983; Fonnum, 1984). Since the work of Krnjević and Phillis (1963), numerous physiological studies have pointed out the almost universally excitatory effects of iontophoretically administered Glu in the cerebral cortex (Dykes et al., 1984; Streit, 1984). The hypothesis that cortical efferent pathways use Glu as their neurotransmitter, first postulated on the basis of physiological data, has gained further support with the introduction of 2 anatomical techniques: retrograde transport of transmitter-related compounds (Streit, 1980; Cuénod et al., 1982; Cuénod and Streit, 1983) and quantitative autoradiography of ${ }^{3} \mathrm{H}$-L-glutamate binding sites (Monaghan et al., 1983; Greenamyre et al., 1984; Halpain et al., 1984). Selective retrograde transport of $\mathrm{D}^{3} \mathrm{H}$-aspartate $\left({ }^{3} \mathrm{H}-\mathrm{D}\right.$-Asp), which is taken up by the same high-affinity mechanisms as the L-forms of Glu and Asp (Balcar and Johnston, 1972), was demonstrated in the cortical projections of the visual cortex to the lateral geniculate nucleus (Baughman and Gilbert, 1981) and of the SI: to the ipsilateral and contralateral cortex (Streit, 1980; Fisher et al., 1982; Barbaresi et al., 1987; Manzoni et al., 1986), to the ventrobasal complex of the thalamus (Rustioni et al., 1983), and to the cuneate nucleus (Rustioni and Cuénod, 1982). In addition, somc corticospinal axons were labeled after ${ }^{3}$ II-D-Asp injections into the dorsal horn of the spinal cord (Rustioni and Cuénod, 1982). For many of these projections, known to arise from layers II, III, V, and VI (Jones, 1984), biochemical data support the anatomical findings (for reviews, see Ottersen and Storm-Mathisen, 1984b; Streit, 1984). The regional distribution of $\mathrm{L}^{-3} \mathrm{H}-\mathrm{Glu}$ binding sites shows that high levels of sodiumindependent binding are present in all the targets of the projections mentioned above (Greenamyre et al., 1984; Halpain et al., 1984).

The finding that some nonpyramidal neurons are labeled by the Glu antiserum, and not by GABA, raises the possibility that some nonpyramidal neurons might use Glu. Nonpyramidal neurons are generally believed to be intrinsic neurons (Lorente de Nó, 1949; Fairén et al., 1984). The present demonstration of Glu-positive nonpyramidal neurons supports the hypothesis that some intrinsic nonpyramidal neurons (mainly spiny stellate and some bipolar neurons) might be excitatory interneurons (Peters and Jones, 1984). However, since some nonpyramidal neurons are callosal projecting neurons (Jacobson and Trojanowski, 1974; Innocenti et al., 1977; Segraves and Rosenquist, 1982; Code and Winer, 1985; Seroogy et al., 1985), it is possible that some of the nonpyramidal, Glu-positive neurons demonstrated in the present study are glutamergic callosal neurons.

Although evidence in favor of a role for Asp as neurotransmitter is less compelling than for Glu (Streit, 1984), there is no reason to exclude it as a putative neurotransmitter of cortical neurons. Recent immunocytochemical studies indicate that the laminar distribution of neurons immunoreactive to an anti-Asp serum produced with the same technique used here is similar to that of Glu-positive neurons (Campistron et al., 1986; Conti et al., 1987). This raises the question of whether Asp- and Gluimmunoreactive neurons are separate populations or whether these amino acids are colocalized in at least some neocortical neurons. Double-labeling experiments reported elsewhere (Conti et al., 1987) indicate that 3 populations of neurons can be distinguished on the basis of Glu and Asp content: The first is immunoreactive only for Glu; the second is immunoreactive only for Asp; and the third (about $10 \%$ of all stained neurons and about $20 \%$ of Glu-positive neurons) is immunoreactive for both Glu and Asp. The latter population is not distinguishable from the other 2 on the basis of laminar distribution or soma size (Conti et al., 1987). This finding raises the possibility that neocortical neurons could exist that use as excitatory neurotransmitters larger molecules such as dipeptides, tripeptides, etc., containing both amino acids. One such molecule, $N$-acetylaspartylglutamate, has recently been under scrutiny as a possible neurotransmitter in the rat hippocampus and piriform cortex (Bernstein et al., 1985; ffrench-Mullen et al., 1985; Koller and Coyle, 1985).

Recent reports have suggested Glu/Asp neurotransmission in some clinical conditions such as epilepsy, ischemic neuronal damage, Alzheimer's dementia, and others (Hicks et al., 1987). The knowledge of the anatomical organization of the cortical glutamergic system might represent a basis for understanding the neuronal changes occurring in several human diseases. For example, the present demonstration of numerous Glu-positive neurons in the supragranular layers of the cerebral cortex might represent a clue to some pathogenetic aspects of Alzheimer's dementia in the light of recent evidence, obtained with the same antibody as that used here, showing an almost complete disappearance of Glu-positive neurons in layers II and III; this suggests that glutamergic corticocortical connections might be impaired to a greater extent than corticofugal pathways in Alzheimer's dementia.

\section{References}

Balcar, V. J., and G. A. R. Johnston (1972) The structural specificity of the high affinity uptake of L-glutamate and aspartate by rat brain slices. J. Neurochem. 19: 2657-2666.

Barbaresi, P., M. Fabri, F. Conti, and T. Manzoni (1987) D-[ $\left.{ }^{3} \mathrm{H}\right]-$ Aspartate retrograde labelling of callosal and association neurones of somatosensory areas I and II of cats. J. Comp. Neurol. (in press).

Battaglia, G., A. Rustioni, R. A. Altschuler, and P. Petrusz (1986) Glutamate immunoreactive neurons in the dorsal root ganglia contain substance P. Soc. Neurosci. Abstr. 12: 333.

Baughman, R. W., and C. D. Gilbert (1981) Aspartate and glutamate as possible neurotransmitters in the visual cortex. J. Neurosci. 1:427439.

Bernstein, J., R. S. Fisher, R. Zaczek, and J. Coyle (1985) Dipeptides of glutamate and aspartate may be endogenous neuroexcitants in the rat hippocampal slice. J. Neurosci. 5: 1429-1433.

Campistron, G., R. M. Buys, and M. Geffard (1986) Specific antibodies against aspartate and their immunocytochemical application in the rat brain. Brain Res. 365: 179-184.

Carroll, E. W., and M. T. T. Wong-Riley (1985) Correlation between cytochrome oxidase staining and the uptake and laminar distribution of tritiated aspartate, glutamate, $\alpha$-aminobutyrate, and glycine in the striate cortex of the squirrel monkey. Neuroscience 15:959-976.

Code, R. A., and J. A. Winer (1985) Commissural neurons in layer III of cat primary auditory cortex (AI): Pyramidal and non-pyramidal cell input. J. Comp. Neurol. 242: 485-510.

Contamina, P., L. Martinez-Miltan, M. J. Pinilla, and J. L. Peña (1984) Morphologically identified neurons which uptake ${ }^{3} \mathrm{H}$-aspartate and 
${ }^{3} \mathrm{H}$-glutamate in the rabbit visual cortex. Trab. Inst. Cajal Invest. Biol. (Suppl.) 75: 101.

Conti, F., A. Rustioni, and P. Petrusz (1985) Morphology and laminar distribution of neurons with glutamate-like immunoreactivity in the rat somatosensory cortex. Soc. Neurosci. Abstr. 11: 755.

Conti, F., A. Rustioni, and P. Petrusz (1986) Neurons immunoreactive for glutamate, GABA and aspartate in the rat somatic sensory cortex: A single and double-labeling study. Soc. Neurosci. Abstr. 12: 797.

Conti, F., A. Rustioni, and P. Pctrusz (1987) Co-localization of glutamate and aspartate immunoreactivity in neurons of the rat somatic sensory cortex. In Excitatory Amino Acid Transmission, T. P. Hicks, D. Lodge, and H. McLennan, eds., pp. 169-172, Alan Liss, New York.

Cuénod, M., and P. Streit (1983) Neuronal tracing using retrograde migration of labeled transmitter related compounds. In Handbook of Chemical Neuroanatomy, Vol. 1, Methods in Chemical Neuroanatomy. A. Björklund and T. Hökfelt, eds., pp. 365-397, Elsevier, Amsterdam.

Cuénod, M., P. Bagnoli, A. Beaudet, A. Rustioni, L. Wiklund, and P. Streit (1982) Transmitter-specific retrograde labeling of neurons. In Cytochemical Methods in Neuroanatomy, V. Chan-Palay and S. L. Palay, eds., pp. 17-44, Alan Liss, New York.

Descarries, L., T. R. Reader, and H. H. Jasper (1984) Monoamine Innervation of the Cerebral Cortex, Alan Liss, New York.

Donoghue, J. P., and S. P. Wise (1982) The motor cortex of the rat: Cytoarchitecture and microstimulating mapping. J. Comp. Neurol. 212: 76-88.

Donoghue, J. P., R. J. Wenthold, and R. A. Altschuler (1985) Localization of glutaminase-like and aspartate aminotransferase-like immunoreactivity in neurons of cerebral neocortex. J. Neurosci. 5: 25972608.

Emson, P. C., and S. P. Hunt (1981) Anatomical chemistry of the cerebral cortex. In The Organization of the Cerebral Cortex, F. O. Schmitt, F. G. Worden, G. Adelman, and S. G. Dennis, eds, pp. 325345, M.I.T. Press, Cambridge, MA.

Emson, P. C., and S. P. Hunt (1984) Peptide-containing neurons. In Cerebral Cortex, Vol. 2, Functional Properties of Cortical Cells, E. G. Jones and A. Peters, eds., pp. 145-169, Plenum, New York.

Fagg, G. E., and A. C. Foster (1983) Amino acid neurotransmitters and their pathways in the mammalian nervous system. Neuroscience 9: 701-719.

Fairén, A., J. DeFelipe, and J. Regidor (1984) Non-pyramidal neurons. General account. In Cerebral Cortex, Vol. 1, Cellular Components of the Cerebral Cortex, A. Peters and E. G. Jones, eds., pp. 201-253, Plenum, New York.

ffrench-Mullen, J. M. H., K. Koller, R. Zaczeb, J. T. Coyle, N. Hori, and D. O. Carpenter (1985) N-acetyl-aspartylglutamate: Possible role as the neurotransmitter of the lateral olfactory tract. Proc. Natl Acad. Sci. USA 82: 3897-3900.

Fisher, B. O., O. P. Ottersen, and J. Storm-Mathisen (1982) Axonal transport of $\mathrm{D}-\left[{ }^{3} \mathrm{H}\right]$-aspartate in the claustrocortical projection. $\mathrm{Neu}-$ roscience (Suppl. 7): S69.

Fitzpatrick, D., J. S. Lund, and D. E. Schmechel (1983) Glutamic acid decarboxylase immunoreactive neurons and terminals in the visual cortex of monkey and cat. Soc. Neurosci. Abstr. 9: 616.

Fonnum, F. (1984) Glutamate: A neurotransmitter in the mammalian brain. J. Neurochem. 42: 1-11.

Gabbott, P. L. A., and P. Somogyi (1986) Quantitative distribution of GABA-immunoreactive neurons in the visual cortex (area 17) of the cat. Exp. Brain Res. 61: 323-331.

Greenamyre, J. T., A. B. Young, and J. B. Penney (1983) Quantitative autoradiography of $\mathrm{L}-\left[{ }^{3} \mathrm{H}\right]$-glutamate binding to rat brain. Neurosci. Lett. 37: 155-160.

Greenamyre, J. T., A. B. Young, and J. B. Penney (1984) Quantitative autoradiographic distribution of $\mathrm{L}-\left[{ }^{3} \mathrm{H}\right]$-glutamate binding sites in rat central nervous system. J. Neurosci. 4: 2133-2144.

Halpain, S., C. M. Wieczorek, and T. C. Rainbow (1984) Localization of L-glutamate receptors in rat brain by quantitative autoradiography. J. Neurosci. 4: 2247-2258.

Hendry, S. H. C., and E. G. Jones (1981) Sizes and distributions of intrinsic neurons incorporating tritiated GABA in monkey sensorymotor cortex. J. Neurosci. I: 390-408.

Hepler, J. R., P. Petrusz, and A. Rustioni (1986a) Antisera to GABA, glutamate and aspartate: Characterization by immunoabsorption and immunocytochemistry. J. Histochem. Cytochem. 34: 110.
Hepler, J. R., C. Toomim, K. D. McCarthy, F. Conti, G. Battaglia, A. Rustioni, and P. Petrusz (1987) Characterization of antisera to glutamate and aspartate. J. Histochem. Cytochem. (in press).

Hicks, T. P., D. Lodge, and H. McLennan (1987) Excitatory Amino Acid Transmission, Alan Liss, New York (in press).

Houser, C. R., S. M. C. Hendry, E. G. Jones, and J. E. Vaughn (1983) Morphological diversity of immunocytochemically identified GABA neurons in the monkey sensory-motor cortex. J. Neurocytol. 12: 617638.

Houser, C. R., J. E. Vaughn, S. H. C. Hendry, E. G. Jones, and A. Peters (1984) GABA ncurons in the cerebral cortex. In Cerebral Cortex, Vol. 2, Functional Properties of Cortical Cells, E. G. Jones and A. Peters, eds., pp. 63-90, Plenum, New York.

Houser, C. R., G. D. Crawford, P. M. Salvaterra, and J. E. Vaughn (1985) Immunocytochemical localization of choline acetyltransferase in rat cerebral cortex: A study of cholinergic neurons and synapses. J. Comp. Neurol. 234: 17-34.

Hsu, S. M., L. Raine, and H. Fanger (1981) Use of avidin-biotinperoxidase complex $(\mathrm{ABC})$ in immunoperoxidase techniques: $\mathrm{A}$ comparison between $\mathrm{ABC}$ and unlabeled antibody (PAP) procedures. J. Histochem. Cytochem. 29: 557-580.

Innocenti, G. M., L. Fiore, and R. Caminiti (1977) Exuberant projection into the corpus callosum from the visual cortex of newborn cats. Neurosci. Lett. 4: 237-242.

Jacobson, S., and J. A. Trojanowski (1974) The cells of origin of the corpus callosum in rat, cat and monkey. Brain Res. 74: 149-155.

Jones, E. G. (1984) Laminar distribution of cortical efferent ceells. In Cerebral Cortex, Vol. 1, Cellular Components of the Cerebral Cortex, A. Peters and E. G. Jones, eds., pp. 521-553, Plenum, New York.

Jones, E. G., and S. H. C. Hendry (1986) Co-localization of GABA and neuropeptides in neocortical neurons. Trends Neurosci. 9: 7176.

Koller, K. J., and J. T. Coyle (1985) The characterization of the specific binding of $\left[{ }^{3} \mathrm{H}\right]-\mathrm{N}$-acetyl-aspartylglutamate to rat brain membranes. J. Neurosci. 5: 2882-2888.

Krnjević, K., and J. W. Phillis (1963) Iontophoretic studies of neurons in the mammalian cerebral cortex. J. Physiol. (Lond.) 165: 274-304.

Lauder, J. M., V. K. M. Han, P. Henderson, T. Verdoorn, and A. C. Towle (1986) Prenatal ontogeny of the GABAergic system in the rat brain: An immunocytochemical study. Neuroscience 19: 465-469.

Lorente de Nó, R. (1949) Cerebral corlex: Architecture, intracortical connections, motor projections. In Physiology of the Nervous System, J. F. Fulton, ed., pp. 288-312, Oxford U. P., New York.

Manzoni, T., Barbaresi, P., and M. Fabri (1986) [ $\left.{ }^{3} \mathrm{H}\right]-\mathrm{D}-a$ aspartate retrograde labelling of association neurons in area SI of the cat. Neurosci. Lett. 67: 175-180.

Maragos, W. F., J. T. Greenamyre, J. B. Penney Jr., and A. B. Young (1987) Glutamate dysfunction in Alzheimer's disease: An hypothesis. Trends Neurosci. 10:65-68.

McGeer, E. G., P. McGeer, and S. Thompson (1983) GABA and glutamate enzymes. In Glutamine, Glutamate and GABA in the Central Nervous System, L. Hertz, E. Kvamme, E. G. McGeer, and A. Schoushoe, eds., pp. 3-17, Alan Liss, New York.

Monaghan, D. T., V. R. Holets, D. W. Toy, and C. W. Cotman (1983) Anatomical distributions of four pharmacologically distinct ${ }^{3} \mathrm{H}-\mathrm{L}-$ glutamate binding sites. Nature 306: 176-179.

Mugnaini, E., and A. L. Dahl (1983) Zinc-aldehyde fixation for light microscopic immunocytochemistry of nervous tissue. J. Histochem. Cytochem. 31: 1435-1438.

Ordronneau, P., P. B. M. Lindström, and P. Petrusz (1981) Four unlabelled antibody bridge techniques: A comparison. J. Histochem. Cytochem. 29: 1397-1404.

Ottersen, O. P., and J. Storm-Mathisen (1984a) Glutamate and GABAcontaining neurons in the mouse and rat brain, as demonstrated with a new immunocytochemical technique. J. Comp. Neurol. 229: 374 392 .

Ottersen, O. P., and J. Storm-Mathisen (1984b) Neurons containing or accumulating transmitter amino acids. In Handbook of Chemical Neuroanatomy, Vol. 3, Classical Transmitters and Transmitter Receptors in the CNS, Part II, A. Björklund, T. Hökfelt, and M. J. Kuhar, eds., pp. 141-246, Elsevier, Amsterdam.

Parnavelas, J. G., and J. K. McDonald (1983) The cerebral cortex. In Chemical Neuroanatomy, P. C. Emson, ed., pp. 505-549, Raven, New York.

Peters, A., and E. G. Jones (1984) Classification of cortical neurons. In The Cerebral Cortex, Vol. 1, Cellular Components of the Cerebral 
Cortex, A. Peters and E. G. Jones, eds., pp. 107-121, Plenum, New York.

Ribak, C. E. (1978) Aspinous and sparsely-spinous stellate neurons in the visual cortex of rats contain glutamic acid decarboxylase. J. Neurocytol. 7: 461-478.

Roberts, E. (1981) Strategies for identifying sources and sites of formation of $\mathrm{G} \wedge \mathrm{B} \Lambda$ precursor or transmitter glutamate in brain. In Glutamate as a Neurotransmitter, G. DiChiara and G. L. Gessa, eds., pp. 91-102, Raven, New York.

Rustioni, A., and M. Cuénod (1982) Selective retrograde transport of $\mathrm{D}$-aspartate in spinal interneurons and cortical neurons of rats. Brain Res. 236: 143-155.

Kustioni, A., D. E. Schmechel, R. Spreafico, S. Cheema, and M. Cuénod (1983) Excitatory and inhibitory amino acid putative neurotransmitters in the ventralis posterior complex: An autoradiographic and immunocytochemical study in rats and cats. In Somatosensory Integration in the Thalamus, G. Macchi, A. Rustioni, and R. Spreafico, eds., pp. 365-383, Flsevier, Amsterdam.

Segraves, M. A., and A. C. Rosenquist (1982) The distribution of the cells of origin of callosal projections in cat visual cortex. J. Neurosci. 2: $1079-1089$

Seguela, P., M. Geffard, R. M. Buijs, and M. Le Moal (1984) Antibodies against $\gamma$-aminobutyric acid: Specificity studies and immunocylochemical results. Proc. Natl. Acad. Sci. USA 81: 3888-3892.

Seroogy, K. B., J. H. Fallon, S. E. Loughlin, and F. M. Leslie (1985) Few cortical cholecystokynin immunoreactive neurons have long projections. Exp. Brain Res. 59: 533-542.

Stefanini, M., DeMartino, C., and Zamboni L. (1967) Fixation of ejaculated spermatozoa for electron microscopy. Nature 26: 173-174.

Sternberger, L. A. (1986) Immunocytochemistry, 3rd ed., Wiley, New York.

Storm-Mathisen, J., and O. P. Ottersen (1986) Antibodies against amino acid neurotransmitters. In Neurohistochemistry: Modern Methods and Applications, P. Panula, H. Päivärinta, and S. Soinila, eds., pp. 107.136, Alan Liss, New York.

Storm-Mathisen, J., A. K. Leknes, A. T. Bore, J. L. Vaaland, P. Edminson, F. M. S. Haug, and O. P. Ottersen (1983) First visualization of glutamate and GABA in neurons by immunocytochemistry. Nature 301: 517-520.

Streit, P. (1980) Selective retrograde labeling indicating the transmitter of neuronal pathways. J. Comp. Neurol. 191: 429-463.

Streit, P. (1984) Glutamate and aspartate as transmitter candidates for systems of the cerebral cortex. In Cerebral Cortex, Vol. 2, Functional Properties of Cortical Cells, E. G. Jones and A. Peters, eds., pp. 119-143, Plenum, New York.

Toomim, C., K. McCarthy, and P. Petrusz (1986) Characterization of antibodies to glutamate and aspartate by immunoblot analysis and immunohistochemistry. Soc. Neurosci. Abstr. 12: 419.

Vacca, L. L., S. L. Rosario, E. A. Zimmerman, P. Tomashefsky, P. Y. $\mathrm{Ng}$, and K. C. Hsu (1975) Application of immunoperoxidase techniques to localize horseradish peroxidase tracer in the central nervous system. J. Histochem. Cytochem. 23: 208-215.

van Eyck, S. L., R. J. Weinberg, F. Conti, P. Petrusz, and A. Rustioni (1986) Glutamate immunoreactivity in rat dorsal column nuclei and substantia gelatinosa. Soc. Neurosci. Abstr. 12: 418 .

Watkins, J. C., and R. H. Evans (1981) Excitatory amino acid transmitters. Annu. Rev. Pharmacol. Toxicol. 21: 165-204.

Weinberg, R. J., F. Conti, S. L. van Eyck, P. Petrusz, and A. Rustioni (1986) Glutamate immunoreactivity in superficial laminae of rat dorsal horn and spinal trigeminal nucleus. In Excitatory Amino Acids Transmission, T. P. Hicks, D. Lodge, and H. McLennan, eds., pp. 173-176, Alan Liss, New York.

Welker, C. (1971) Microelectrode delineation of fine grain somatotopic organization of SmI cerebral neocortex in albino rat. Brain Res. 26: 259-275.

Wong-Riley, M. T. T. (1979) Changes in the visual system of monocularly sutured or enucleated cats demonstrable with cytochrome oxidase histochemistry. Brain Res. 171: 11-28.

Woolsey, C. N., and D. H. LeMessurier (1948) The pattern of cutaneous representation in rat's cerebral cortex. Fed. Proc. $7: 137-138$.

Zilles, K., B. Zilles, and A. Schleicher (1980) A quantitative approach to cytoarchitectonics. VI. The areal pattern of the cortex of the albino rat. Anat. Embryol. 159: 335-360. 